Carta ao Editor

Letter to the Editor

Ana Maria Bezerra de Araújoํㅜㄹ José Márcio Carvalho da Silva ${ }^{2,3}$ (1)

Leandro Pernambuco $0^{1,4}$

\section{Cuidados específicos com laringectomizados totais durante a pandemia de COVID-19 na realidade brasileira}

\section{Specific care for total laryngectomized patients during the COVID-19 pandemic in the Brazilian reality}

Endereço para correspondência: Leandro Pernambuco

Departamento de Fonoaudiologia, Universidade Federal da Paraíba UFPB

Cidade Universitária, João Pessoa (PB), Brasil, CEP: 58051-900. E-mail: leandroape@globo.com

Recebido em: Maio 28, 2020.
Desde o primeiro trimestre de 2020, o mundo vem enfrentando a pandemia da Coronavirus Disease 19 (COVID-19), doença causada pelo novo coronavírus SARS-Cov- $2^{(1)}$. Várias medidas de prevenção e controle de disseminação da doença foram adotadas para a população em geral, porém, existem alguns grupos mais suscetíveis ao risco de contágio e que necessitam de cuidados específicos, dentre eles, os laringectomizados totais ${ }^{(2)}$.

Essa população é composta, em sua maioria, por idosos imunossuprimidos com múltiplas comorbidades, nos quais a traqueostomia definitiva permite a passagem de fluxo aéreo não filtrado e umidificado diretamente para as vias aéreas inferiores, o que aumenta a incidência de infecções broncopulmonares ${ }^{(3)}$ e naturalmente os expõe à natureza contagiosa do SARS-Cov-2 por meio de gotículas respiratórias e aerossolização(2).

Uma das opções para minimizar a vulnerabilidade dos laringectomizados totais à COVID-19 é o uso do Heat and Moisture Exchange (HME), um dispositivo permutador de calor e umidade constituído por uma esponja de espuma impregnada com cloreto de cálcio $^{(4)}$ colocada sobre uma vedação hermética em volta do estoma traqueal ${ }^{(5)}$. Esses filtros adicionam resistência ao fluxo aéreo, além de filtrar, aquecer e umidificar o ar, o que reduz a necessidade de recorrer a umidificadores e vaporizadores externos e otimiza o desempenho pulmonar ${ }^{(6,7)}$. Além disso, o uso do HME minimiza o risco de transmissão viral por aerossolização das secreções traqueais, já que o dispositivo reduz os episódios de tosse, produção de escarro e expectoração ${ }^{(2,5,8)}$.

Existem HME com filtros bacterianos e/ou virais específicos ${ }^{(8)}$ que possuem poros menores que 0.6 mícrons e conseguem reter alguns patógenos (bactérias e vírus), exercendo o papel de barreira biológica contra infecções pulmonares ${ }^{(9)}$, o que é especialmente importante no contexto da pandemia de COVID-19, considerando que as partículas do SARS-Cov-2 possuem o tamanho estimado de 0.12 mícrons $^{(10)}$.

Embora a eficácia dos permutadores de calor e umidade na prevenção da COVID-19 ainda não tenha sido especificamente testada, pressupõe-se que o HME feito de material de filtragem eletroestática, cujo percentual de filtração viral é mais elevado, é o tipo

Trabalho realizado no Departamento de Fonoaudiologia, Universidade Federal da Paraíba - UFPB - João Pessoa (PB), Brasil.

${ }^{1}$ Apta Comunicação - Recife (PE), Brasil.

${ }^{2}$ Faculdade da Escada - FAESC - Escada (PE), Brasil.

${ }^{3}$ Universidade Federal de Pernambuco - UFPE - Recife (PE), Brasil

${ }^{4}$ Universidade Federal da Paraíba - UFPB - João Pessoa (PB), Brasil.

Fonte de financiamento: nada a declarar.

Conflito de interesses: nada a declarar. 
mais indicado para uso durante a pandemia ${ }^{(2,8,11)}$. É necessário destacar ainda que a fixação do HME requer acessórios como adesivos hipoalergênicos descartáveis ${ }^{(2)}$ ou cânula específica de traqueostomia em silicone ${ }^{(12)}$. Todo esse aparato tem um custo pouco acessível à maioria dos laringectomizados totais no contexto brasileiro de desigualdade socioeconômica. Além disso, a ausência de uma política nacional de atenção à saúde do laringectomizado total dificulta o acesso aos insumos de proteção pulmonar nesse momento de pandemia.

Alguns institutos legais amparam essa população como, por exemplo, a Portaria SAS/MS no 400, de 16/11/2019(11), que estabelece diretrizes nacionais para a atenção à saúde das pessoas ostomizadas; a Lei $\mathrm{n}^{\mathrm{0}} 13.146$, de 6/11/2015(13), que institui o Estatuto da Pessoa com Deficiência; e, mais recentemente, a Deliberação 202/CIB/2019 ${ }^{(14)}$, da Secretaria de Estado da Saúde de Santa Catarina, publicada em 26/9/2019, que, com apoio da Associação de Câncer de Boca e Garganta (ACBG - Brasil), instituiu as Diretrizes para Atenção à Saúde das Pessoas Laringectomizadas e/ou Traqueostomizadas e a padronização da dispensação dos insumos necessários para reabilitação pulmonar e fonatória no referido estado, incluindo o HME. Trata-se de uma iniciativa pioneira com base legal cujo exemplo deve ser seguido por outros estados da federação. Ainda em razão das dificuldades de obtenção dos insumos por via administrativa, alguns usuários recorrem à Justiça para garantir o fornecimento. Em 2019, no Rio de Janeiro, por exemplo, um usuário ingressou com essa demanda contra o poder público e teve seu requerimento deferido, conforme o entendimento favorável do magistrado ${ }^{(15)}$.

A pandemia de COVID-19 tem evidenciado a necessidade de cuidados específicos com os laringectomizados totais e, ao mesmo tempo, a carência do poder público em fornecer o suporte necessário a esses usuários. A melhor recomendação disponível no momento para essa população, para garantir a proteção contra a aerossolização e inalação do SARS-Cov-2 no ambiente comunitário, consiste em três condutas: 1) cobrir nariz e boca com máscara cirúrgica ou de tecido; 2) cobrir estoma com vestuário de gola alta ou cachecol; 3) usar HME com filtros bacterianos e/ou virais específicos ${ }^{(8)}$. Na inviabilidade do acesso ao HME, os laringectomizados totais devem ser amplamente orientados a manter as demais condutas. Ao mesmo tempo, o momento também deve ser aproveitado para dar visibilidade às necessidades e vulnerabilidades desse grupo.

\section{REFERÊNCIAS}

1. WHO: World Health Organization. Coronavirus disease (COVID-19) outbreak situation [Internet]. Geneva: WHO; 2019 [citado em 2020 Abr 20]. Disponível em: https://www.who.int/emergencies/diseases/novelcoronavirus-2019

2. Parrinello G, Missale F, Sampieri C, Carobbio ALC, Peretti G. Safe management of laryngectomized patients during the COVID-19 pandemic. Oral Oncol. 2020;107:104742. http://dx.doi.org/10.1016/j.oraloncology.2020.104742.

3. Mérol JC, Charpiot A, Langagne T, Hémar P, Ackerstaff AH, Hilgers FJ. Randomized controlled trial on postoperative pulmonary humidification after total laryngectomy: external humidifier versus heat and moisture exchanger. Laryngoscope. 2012;122(2):275-81. http://dx.doi.org/10.1002/ lary.21841. PMid:22105893.
4. Hilgers FJ, Aaronson NK, Ackerstaff AH, Schouwenburg PF, van Zandwikj N. The influence of a heat and moisture exchanger (HME) on the respiratory symptoms after total laryngectomy. Clin Otolaryngol Allied Sci. 1991;16(2):152-6. http://dx.doi.org/10.1111/j.1365-2273.1991. tb01966.x. PMid:2070531.

5. Araujo AMB, Santos ECB, Pernambuco LA. Breathing and voice self-assessments after the use of a heat and moisture exchange in total laryngectomyzed patients. Audiol Commun Res. 2017;22:e1820.

6. Scheenstra RJ, Muller SH, Vincent A, Ackerstaff AH, Jacobi I, Hilgers FJ. Short-term endotracheal climate changes and clinical effects of a heat and moisture exchanger with an integrated electrostatic virus and bacterial filter developed for laryngectomized individuals. Acta Otolaryngol. 2010;130(6):739-46. http://dx.doi.org/10.3109/00016480903382790. PMid:20001445.

7. Brook I, Bogaardt H, van As-Brooks C. Long-term use of heat and moisture exchangers among laryngectomees: medical, social, and psychological patterns. Ann Otol Rhinol Laryngol. 2013;122(6):358-63. http://dx.doi. org/10.1177/000348941312200602. PMid:23837386.

8. Hennessy M, Bann DV, Patel VA, Saadi R, Krempl GA, Deschler DG, et al Commentary on the management of total laryngectomy patients during the COVID-19 pandemic. Head Neck. 2020;42(6):1137-43. http://dx.doi. org/10.1002/hed.26183. PMid:32298016.

9. van den Boer C, van Harten MC, Hilgers FJ, van den Brekel MW, Retèl VP. Incidence of severe tracheobronchitis and pneumonia in laryngectomized patients: a retrospective clinical study and a European-wide survey among head and neck surgeons. Eur Arch Otorhinolaryngol. 2014;271(12):3297303. http://dx.doi.org/10.1007/s00405-014-2927-4. PMid:24554391.

10. Zhu N, Zhang D, Wang W, Li X, Yang B, Song J, et al. A novel coronavirus from patients with pneumonia in China, 2019. N Engl J Med. 2020;382(8):72733. http://dx.doi.org/10.1056/NEJMoa2001017. PMid:31978945.

11. Brasil. Ministério da Saúde. Portaria no 400, de 16 de novembro de 2009. Estabelece Diretrizes Nacionais para a Atenção à Saúde das Pessoas Ostomizadas no âmbito do Sistema Único de Saúde - SUS [Internet]. Diário Oficial da União; 18 nov 2009 [citado em 26 Maio 2020]. Disponível em: https://bvsms.saude.gov.br/bvs/saudelegis/sas/2009/prt0400_16_11_2009. $\mathrm{html}$

12. Kligerman MP, Vukkadala N, Tsang RKY, Sunwoo JB, Holsinger FC, Chan JYK, et al. Managing head and neck cancer patients with tracheostomy or laryngectomy during the COVID-19 pandemic. Head Neck. 2020;42(6):120913. http://dx.doi.org/10.1002/hed.26171. PMid:32298035.

13. Brasil. Secretaria-Geral. Subchefia para Assuntos Jurídicos. Lei no ${ }^{\circ} 13.146$, de 6 de novembro de 2015. Institui a Lei Brasileira de Inclusão da Pessoa com Deficiência (Estatuto da Pessoa com Deficiência). [Internet]. Diário Oficial da União; 7 jul 2015 [citado em 26 Maio 2020]. Disponível em: http://www.planalto.gov.br/ccivil_03/_ato2015-2018/2015/lei/113146.htm

14. Santa Catarina. Governo. Secretaria de Estado da Saúde. Comissão Intergestores Bipartite. Deliberação 202/CIB/2019, de 26 de setembro de 2019. Aprova as Diretrizes Para Atenção à Saúde das Pessoas Laringectomizadas e/ou Traqueostomizadas do Estado de Santa Catarina; Aprova os formulários padronizados pelo Serviço Estadual; Estabelece os fluxos e competências de cada ponto da Rede para o referido Serviço [Internet]. Diário Oficial do Estado de Santa Catarina [citado em 26 Maio 2020]. Disponível em: http:// www.saude.sc.gov.br/index.php/documentos/legislacao-principal/deliberacoescib/deliberacoes-2019-cib/16046-deliberacao-202-cib-26-09-2019/file

15. Brasil. Tribunal Regional Federal da $2^{\mathrm{a}}$ Região. Andamento do Processo $n$. 5073010-56.2019.4.02.5101/RJ - Procedimento Comum - 18/11/2019 do TRF-2 [Internet]. Jusbrasil; 2019 [citado em 26 Maio 2020]. Disponível em: https://www.jusbrasil.com.br/diarios/271707637/trf-2-jud-jfrj-18-112019-pg-93?ref=topic-lawsuit

\section{Contribuição dos autores}

AMBA e LP contribuiram com a concepção da ideia, seleção de referências, redação e revisão final do texto; JMCS contribuiu com seleção de referências, redação e revisão final do texto. 